\title{
THE EFFECT OF MICROWAVE TREATMENT AND DELAYED HARVESTING ON OIL PALM FRUITLETS (Elaeis guineensis) OIL QUALITY
}

\author{
NU'MAN ABDUL HADI ${ }^{1 *}$; NG MEI HAN ${ }^{1}$; RUSNANI ABD MAJID ${ }^{1}$ and CHE RAHMAT CHE MAT ${ }^{1}$
}

\begin{abstract}
Conventional palm oil mill practice not only processes unwanted empty bunches in sterilisation stage but also produces large amount of wastewater. The oil extraction rate (OER) of the mill is affected by the quality of the oil palm fresh fruit bunches (FFB), which may consist of unripe fruit with less oil content, and uneven distribution of steam throughout the bunches during sterilisation. Besides the FFB, oil palm mills also process loose fruits either collected from the plantations or detached during FFB transportation to the mills. As these loose fruitlets are void of the stalk and core of the bunch, processing them in the same way as FFB is not cost effective. The objective of this study was to carry out processing of fruitlets using microwave, followed by solvent extraction. Loose fruitlets detached in plantations usually come from the outer layer of bunch which contains more oil compared to the inner layer. The following methodology was adopted in this study: 1) optimisation of load per batch for microwave processing of fruitlets, 2) optimisation of microwave heating parameters, and 3) processing of fruitlets detached from the same bunch over 21 days. Fruitlets were sterilised via microwave $(2.4 \mathrm{GHz}, 900 \mathrm{~W}$, medium power) and its oil is extracted by n-hexane. Optimum load of 170-220 g fruitlets per batch with 3 min heating left the fruitlets to be well conditioned, i.e., softened mesocarp and unburned kernel. The fruitlets get heated rapidly by microwave due to instantaneous dielectric heating effect of moisturised materials. Quality of oil extracted from fruits detached from the same bunch collected over 21 days was investigated. Free fatty acids (FFA), deterioration of bleachability index (DOBI), and oxidative stability of the oil was found to have reduced from $1.3 \%, 4.32$ and $15.18 \mathrm{hr}$ to $6.5 \%, 0.86$ and $5.28 \mathrm{hr}$, respectively.
\end{abstract}

Keywords: crude palm oil quality, detached palm fruits, microwave, $n$-hexane extraction.

Received: 17 November 2020; Accepted: 29 January 2021; Published online: 20 April 2021.

\section{INTRODUCTION}

Palm (Elaeis guineensis) oil is currently the world's largest vegetable oil consumed for food, followed by soybean and rapeseed oil (Kushairi et al., 2018; Statista, 2019). The production of crude palm oil (CPO) has increased tremendously since early 1950 s following the increase in world population, hence

\footnotetext{
Malaysian Palm Oil Board,

6 Persiaran Institusi, Bandar Baru Bangi,

43000 Kajang, Selangor, Malaysia.

* Corresponding author e-mail: numan@mpob.gov.my
}

the increasing demand (Ahmad Borhan et al., 2004; Ramli, 2011). The key contribution for producing large amount of CPO relies mainly on high oil content of palm fruits and effective processing of the palm fresh fruit bunch (FFB) in the milling process. In order to adapt to demand and land availability, development of a technology in harvesting and milling operation is growing fast. Oil extraction rate (OER) is one of the performance parameters for milling process (Parveez, et al., 2020). To date, development of new technologies to achieve higher OER focuses on faster ways to harvest and collect FFB, low cost FFB transportation system, and high 
efficiency milling process (Kushairi and Abd Rahim, 2017). By transporting only the fruitlets, leaving the empty fruit bunches (EFB) in the plantation, might benefit the palm oil industry in many ways; 1) reduce FFB transportation cost from the plantation to the mill, 2) increase in OER as processing is carried out on only fruitlets, emitting the stalk, and 3) reduce transportation cost in sending back the EFB to the plantation, as illustrated in Figure 1. However, as fruitlets from the same bunch do not ripen and detach at the same time, there is a risk of deterioration due to delayed processing. Therefore, one of the objectives of this study was to determine the rate of deterioration in oil quality when harvesting of FFB is delayed up to 21 days after the first fruitlets dropped. A typical FFB harvesting interval (HI) is 7-10 days, with FFB yield starting to decline if the $\mathrm{HI}$ is extended beyond 20 days (Corley and Tinker, 2015).

Steam production for FFB sterilisation consumes huge amount of water. Almost half of the steam used is exhausted during sterilisation cycle and the remainder ends up as steriliser condensate, which forms part of the palm oil mill effluent (POME) (Ahmed et al., 2015). Adoption of microwave heating technology for the processing of palm oil may reduce, if not eliminate, the use of water. Microwave heating is also known as dielectric heating as the heating depended on dielectric properties of the materials. Microwave works by the principle of resonation of electrons at high frequency created by magnetron, a device consisting of a permanent magnet responsible for creating a magnetic field. The microwave generated is distributed and absorbed by the component (e.g. food) leading to rise in temperature. The capability to absorb microwave energy is governed by the material's dielectric properties where water is the major absorber of microwave energy (Sosa-Morales et al., 2010). Consequently, the higher the moisture content, the better the heating. Dielectric materials convert electric energy at microwave frequency into heat, where temperature rise of a material can be calculated as in the Equation (1):

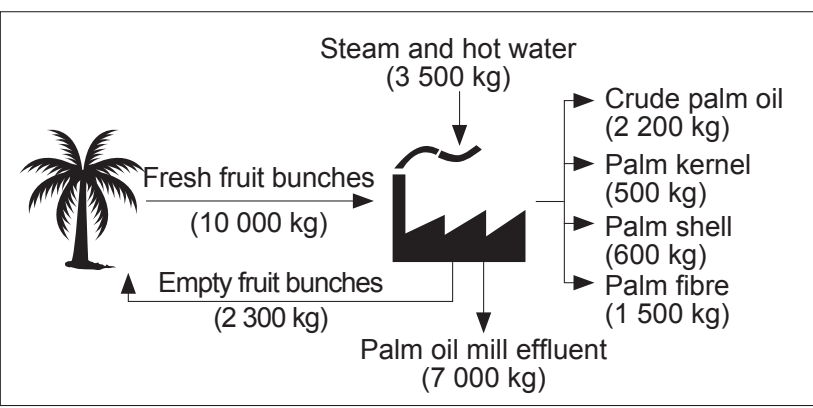

(a)

$$
\rho C_{p} \frac{d T}{d t}=55.63 \times 10^{-12} f E^{2} \varepsilon^{\prime \prime}
$$

where $C_{p}$ is the specific heat of the material in $\mathrm{J} \mathrm{kg}^{-1}$ ${ }^{\circ} \mathrm{C}^{-1}, \rho$ is the density of the material in $\mathrm{kg} \mathrm{m}^{-3}, E$ is the root mean square of electric field intensity in $\mathrm{V}$ $\mathrm{m}^{-1}, f$ is the frequency in $\mathrm{Hz}, d \mathrm{~T} / \mathrm{dt}$ is the time rate of the temperature increase in ${ }^{\circ} \mathrm{C} \mathrm{s}^{-1}$ and $\varepsilon$ is the loss factor of the material (Komarov et al., 2005). As palm fruitlet contains about 20\% moisture, it gets heated quickly and gave rise to temperature. However, because of the rapid heating, the moisture within is vapourised rapidly as well, leaving the fruits dried, which may obstruct depericarping of the fruitlets. Effect of prolonged microwave heating on palm fruitlets conditions was investigated in this study.

Several studies on sterilisation of oil palm fruit using microwave were reported in the past (Chow and Ma, 2007; Cheng and Chuah, 2011; Sarah, 2018; Sukaribin and Khalid, 2009; Umudee et al., 2013). Sterilisation of whole palm fruit bunch using microwave shortens the sterilisation duration to less than $10 \mathrm{~min}$ as compared to conventional steam sterilisation which takes 60-90 min (Chow and Ma, 2007; Kandiah et al., 2006). However, microwave heating worked only on the outer layer of the FFB due to limitation of microwave to penetrate inner layer of the bunch (Chow and Ma, 2007; Sukaribin and Khalid, 2009). Without the stalk and core of the FFB, microwave sterilisation would be much more efficient and effective.

When FFB are sent to the mills, some of the fruitlets tend to detach themselves from the bunch during transportation. Besides this, loose fruits that fall on the ground are also collected during FFB harvesting. These loose fruitlets present the opportunity for revamping the palm oil milling process by changing how sterilisation is carried out. As such, one of the objectives of this study was to study the effect of microwave heating or sterilisation on the oil palm fruitlets and the quality of oil obtained from them.

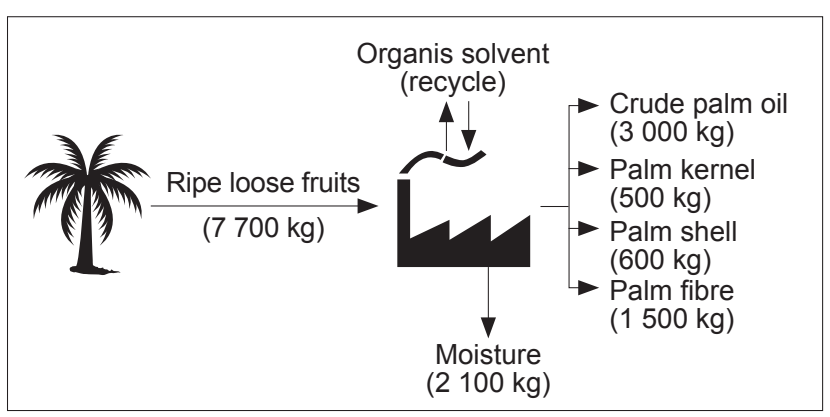

(b)

Figure 1. Illustration on (a) conventional practice for the processing of fresh fruit bunch (FFB) to produce crude palm oil and (b) new proposed practice to process only the ripe detached fruits using microwave and solvent extraction. 
Microwave heating of the whole FFB was not feasible due to uneven heat distribution and inefficient bunch stripping, where a series of heating is required to achieve 100\% stripping efficiency (Sukaribin and Khalid, 2009). Heating of only loose fruitlets is deemed to be a better approach. However, the loose fruits collected in the plantations during FFB harvesting and those detached during FFB transportation to the mills accounted to only $8 \%-10 \%$ of the total fruits processed by the mill daily (Corley and Tinker, 2015). To make microwave heating feasible, larger amount of fruitlets to be processed is needed. This can be done by removing the stalk and core of the bunch prior to sterilisation. A different set of machineries is needed for this. A more natural approach was tested in this study whereby the FFB is not harvested, but rather, the fruitlets were let to ripen, detached and fall on the ground naturally. The fruitlets were then collected from the ground daily for up to 21 days and sent to the mill for processing while the nearly empty bunch was cut from the tree on the $21^{\text {st }}$ day.

In conventional milling practice, the oil is squeezed out of the digested fruits mash via mechanical screw press after sterilisation. The digested mash undergoes progressive pressure when it passes through the scroll of the screw having diminished pinch, leaving behind 7\%-8\% residual oil in the press cake (George, 2011). In comparison, solvent extraction with $n$-hexane will recover almost all, leaving about $0.5 \%$ residual oil, ensuring high OER for palm oil mills (George, 2011). It is relatively efficient and reliable, which is one of the reasons why solvent extraction is the primary means of separating large tonnages of oil from low oil-bearing seeds such as soybean, rapeseed, canola and sunflower.

Microwave heating, followed by extraction of oil by way of solvent extraction is deemed to be an excellent processing combination to increase the OER of the mill. However, the quality of the oil obtained from this manner has not been thoroughly studied. Oil obtained through solvent extraction may have completely different profile and properties than those obtained via screw pressing. As such, the third objective of this study was to determine the quality of oil obtained via microwave heating and solvent extraction.

\section{MATERIALS AND METHODS}

\section{Materials}

Palm fruits were obtained from a palm oil mill and oil palm plantation in Negeri Sembilan, Malaysia. Two fruits collection methods were carried out: 1) collection of loose fruits at oil palm
FFB receiving ramp in the mill for microwave treatment optimisation study and 2) daily collection of detached palm fruitlets in plantation for 21 days to study the changes in oil quality.

Solvents and chemicals were obtained as follows: $n$-hexane (99\%), tetrahydrofuran (99\%), 2-propanol (99\%) for analyses were purchased from Merck (Darmstadt, Germany), sodium hydroxide, ethylalcohol $(95 \%), n$-hexane $(95 \%)$ for extraction were purchased from R\&M (Essex, United Kingdom), phosphoric acid (85\%) was purchased from Friendemann Schmidt (Perth, Australia), potassium hydrogen phthalate was purchased from Systerm (Selangor, Malaysia) and phenolphthalein was purchased from LabChem (Australia).

\section{Microwave Treatment and Oil Extraction}

Approximately $200 \mathrm{~g}$ of palm fruitlets were heated in a domestic microwave oven (Panasonic, Model NN-CD9975, 42 litres, 900 W, 2.4 GHz) at medium power intensity. Duration of heating varied from 1-5 min. After microwave heating, the palm fruitlets were then peeled and the nuts within were separated from the mesocarp. The oil in mesocarp was extracted by $n$-hexane using Soxhlet apparatus for $4 \mathrm{hr}$. The solvent-to-fruit ratio $(1.5: 1, \mathrm{v} / \mathrm{w})$ was kept constant for all extraction processes.

\section{Analyses of Palm Oil}

Free fatty acid (FFA) content, deterioration of bleachability index (DOBI), carotene content and phosphorus content were determined following the MPOB Standard Test Method (Ainie et al., 2005). A Thermo Fisher Scientific (Model Helios Zeta) UV-Vis spectrophotometer was used for the determination of DOBI and carotenes content.

Vitamin E content was determined by high performance liquid chromatography (Waters 600) equipped with a photodiode array detector (Waters 996) with a silica column (150 $\mathrm{mm} \times 4.6 \mathrm{~mm})$. Mobile phase was hexane, tetrahydrofuran, isopropanol (95:4:1, v/v/v) with flowrate of $1.5 \mathrm{ml} \mathrm{min}^{-1}$.

Oxidative stability of oil was determined using a 743 Rancimat (Metrohm, Herisau, Switzerland). $2.5 \mathrm{~g}$ oil (warmed at $60^{\circ} \mathrm{C}$ ) was weighed and placed at the bottom of the reaction tube. The heating block temperature and air flow were set at $120^{\circ} \mathrm{C}$ and 20 litres $\mathrm{hr}^{-1}$, respectively.

Bleachability test was carried out in nitrogen blanket as follows: $100 \mathrm{~g}$ oil was pre-heated at $90^{\circ} \mathrm{C}$ in a round bottom flask, then $0.1 \mathrm{wt} \%$ phosphoric acid ( $1 \mathrm{ml}$ of solution drawn from $1 \mathrm{~g}$ of phosphoric acid dissolved in $10 \mathrm{ml}$ distilled water) was added and the mixture was heated to $90^{\circ} \mathrm{C}$ for $10 \mathrm{~min}$. $1 \mathrm{~g}$ bleaching earth was then added to the mixture, followed by increase in temperature to $105^{\circ} \mathrm{C}$ and 
maintained for $15 \mathrm{~min}$. Thereafter, the mixture was immediately filtered under vacuum. About $90 \mathrm{~g}$ of the mixture was then transferred to a pre-heated apparatus and further refined at $260^{\circ} \mathrm{C}$ for $30 \mathrm{~min}$ under vacuum. The refined oil was cooled to $60^{\circ} \mathrm{C}$ and vacuum was released. The sample was then kept for further analysis.

\section{RESULTS AND DISCUSSION}

\section{Microwave Treatment of Oil Palm Fruitlets}

In microwave heating, the rise in temperature is proportional to the electric field intensity and heating duration, while inversely proportional to the density of the material (Equation 1). Therefore, heating effect may vary subjected to heating duration, power intensity and weight of sample. The optimum heating duration of the oil palm fruitlets was determined to be $3 \mathrm{~min}$. Lower heating effect was expected with the increased in number of fruitlets heated per batch. Batch with 14 to 18 (170-220 g) fruitlets was well cooked as shown in Table 1. Mesocarp became dry and kernel was burnt due to overheating when less than $170 \mathrm{~g}$ fruitlets were heated. Vice versa, heating more than $220 \mathrm{~g}$ fruitlets led to insufficient conditioning of the palm fruitlets and is not desired.

Table 2 and Figure 2 depict the condition and visual of the oil palm fruits upon heating by microwave at various heating durations. In conventional practice, steam is used as medium to distribute heat into inner layers of the FFB. Microwave heating in dry conditions exposed the oil palm fruits to potential burning. Therefore, microwave heating duration played a crucial role in ensuring the heated fruits remain in good condition for subsequent oil extraction.

TABLE 1. CONDITION OF FRUITLETS BASED ON VARIOUS HEATING LOADS

\begin{tabular}{cccc}
\hline \multirow{2}{*}{$\begin{array}{c}\text { Number } \\
\text { of fruitlets }\end{array}$} & Weight $(\mathbf{g})$ & \multicolumn{2}{c}{ Condition of the heated fruits } \\
\cline { 2 - 4 } 2 & 24.8 & Mesocarp & Kernel \\
\hline 4 & 49.9 & Dry, stiff & Brown \\
6 & 75.1 & Dry, stiff & Brown \\
8 & 97.5 & Partially dry & Brown \\
10 & 120.5 & Partially dry & Slightly brown \\
12 & 149.6 & Oily, soft & Slightly brown \\
14 & 171.0 & Oily, soft & White \\
16 & 200.2 & Oily, soft & White \\
18 & 221.5 & Oily, soft & White \\
20 & 246.0 & No changes & White \\
\hline
\end{tabular}

Note: 3 min microwave heating, medium power intensity.
TABLE 2. CONDITION OF THE OIL PALM FRUITS AFTER MICROWAVE HEATING

\begin{tabular}{cccc}
\hline \multirow{2}{*}{$\begin{array}{c}\text { Heating } \\
\text { duration } \\
\text { (min) }\end{array}$} & $\begin{array}{c}\text { Other } \\
\text { parameters }\end{array}$ & \multicolumn{2}{c}{ Condition of the heated fruits } \\
\cline { 3 - 4 } & & Mesocarp & Kernel \\
\hline 1 & Weight of & No changes & White \\
2 & fruits: & Oily and soft & White \\
3 & $200 \pm 10 \mathrm{~g}$ & Oily and soft & White \\
4 & Power & Partially dry & Slightly brown \\
5 & intensity: & Dry and stiff & Completely brown \\
\hline
\end{tabular}

Note: 3 min microwave heating, medium power intensity.

Heat penetration is the key factor in palm fruitlets sterilisation via microwave heating. Notably, oil yield increased with increasing heating duration. Table 3 shows the yield and quality of the oil obtained through solvent extraction of the microwave heated oil palm fruit. In order to maximise oil extraction from the mesocarp and preserving the nuts for subsequent process, an optimum heating duration that does not affect the kernel is needed. Besides the purpose to maximise oil extraction, hardened mesocarp as a result of prolonged microwave heating make depericarping operation difficult. Results showed that the increase of heating duration of up to $5 \mathrm{~min}$ increased the oil yield. Moderate heating duration of 2-3 min was optimum to loosen the nut from its mesocarp, while keeping the kernel in good condition for further processing. After 4-5 min heating, the mesocarp became dried due to excessive loss of moisture (vapourised), but otherwise still in good condition, making oil extraction easier. Extraction using $n$-hexane is enhanced through better interaction of the solvent with the oil. On the other hand, presence of moisture increased the polarity of the fruits, thus, oil extraction is hindered.

Comparisons on oil quality were made with CPO obtained from palm oil mill (Table 4). MCPO refers to mesocarp oil obtained from palm fruitlets that were subjected to $3 \mathrm{~min}$ microwave heating and solvent extraction. FFA and DOBI of the MCPO passed the trading specifications limit set by the Palm Oil Refiners Association of Malaysia (PORAM), and were superior compared to CPO. However, the superior quality could be due to more prudent handling as MCPO was obtained through laboratory-scale experiment compared to $\mathrm{CPO}$ which was produced in commercial scale. Commercial production of $\mathrm{CPO}$ took hours, from gate to storage tank, therefore gave room for quality deterioration along the process.

\section{Bleachability of Solvent-extracted Palm Oil}

DOBI measurement was recommended by Swoboda (1982) in 1980s as rapid assessment on the 


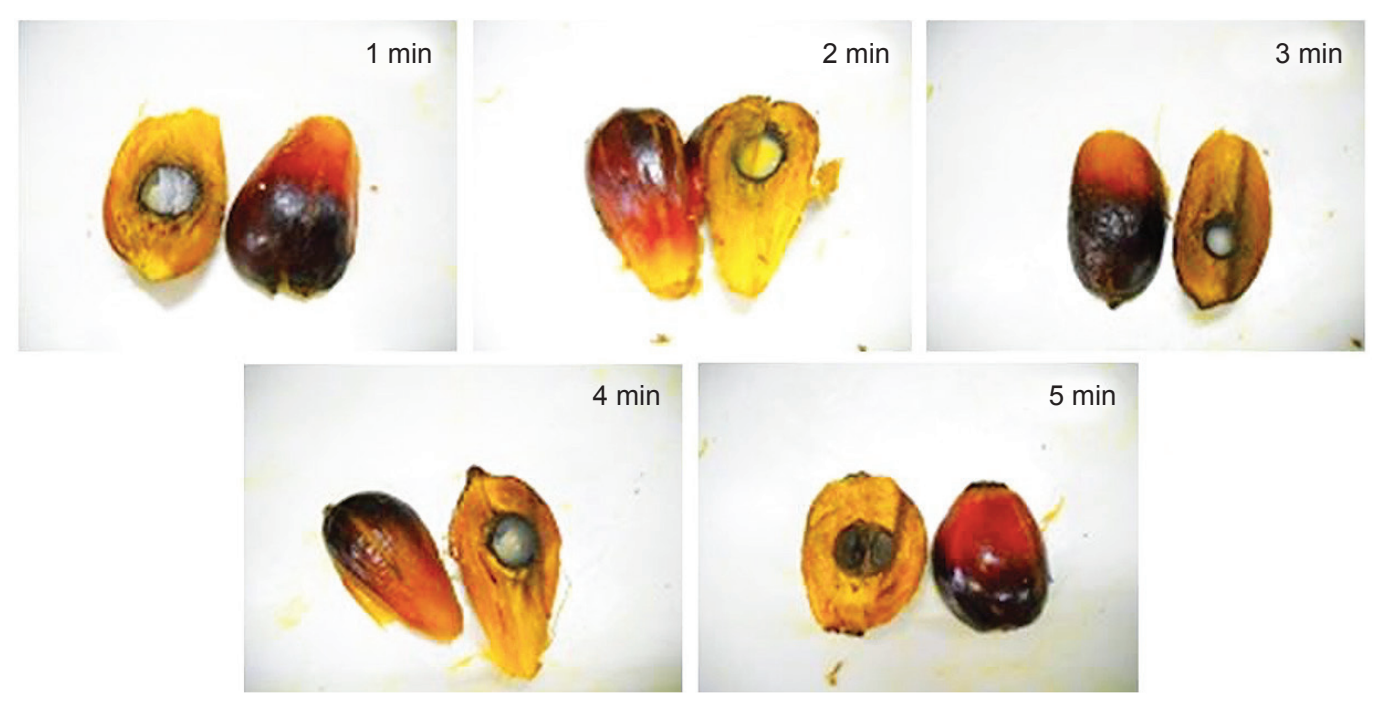

Figure 2. Visual of the oil palm fruits after heated in microwave.

TABLE 3. EFFECT OF MICROWAVE HEATING DURATION ON OIL YIELD AND QUALITY

\begin{tabular}{cccccc}
\hline $\begin{array}{c}\text { Heating duration } \\
(\mathbf{m i n})\end{array}$ & Other parameters & $\begin{array}{c}\text { Oil yield } \\
(\mathbf{w t} \%)\end{array}$ & $\begin{array}{c}\text { Free fatty acid } \\
\mathbf{( \% )}\end{array}$ & DOBI & $\begin{array}{c}\text { Oxidative stability } \\
\text { (hr) }\end{array}$ \\
\hline 1 & & 16.8 & 1.69 & 3.77 & 17.67 \\
2 & Weight of fruits: & 25.0 & 1.61 & 3.97 & 19.07 \\
3 & $200 \pm 10 \mathrm{~g}$ & 32.3 & 0.87 & 4.48 & 18.94 \\
4 & Power intensity: & 32.5 & 0.86 & 4.75 & 17.78 \\
5 & Medium & 36.6 & 0.68 & 4.07 & 18.09 \\
\hline
\end{tabular}

Note: DOBI - deterioration of bleachability index.

\section{TABLE 4. COMPARISONS OF OIL QUALITY}

\begin{tabular}{lccc}
\hline \multicolumn{1}{c}{ Parameter } & CPO & MCPO & Limit \\
\hline FFA $(\%)$ & 3.44 & 1.14 & 5.0 (max.) \\
DOBI (unitless) & 2.9 & 4.2 & 2.3 (min.) \\
Oxidative stability (hr) & 15.92 & 18.31 & - \\
Carotene (mg kg-1) & 589 & 624 & $\begin{array}{c}500-700 \\
\text { (range) }\end{array}$ \\
Vitamin E (mg kg-1) & 802 & 1347 & $\begin{array}{c}600-1000 \\
\text { (range) }\end{array}$ \\
\hline
\end{tabular}

Note: DOBI - deterioration of bleachability index; FFA - free fatty acid; $\mathrm{CPO}$ - crude palm oil; $\mathrm{MCPO}$ - mesocarp oil obtained from microwave heated ( $3 \mathrm{~min}$, medium power) palm fruits.

ease of refining for CPO. The DOBI measurement, which was defined as ratio of spectrophotometric measurements of a CPO solution at $446 \mathrm{~nm}$ and 269 $\mathrm{nm}$ was widely used for mechanically pressed CPO in Malaysian palm oil industry for quality control (Lin and Gee, 2001). The process of refining removes gums (in the form of phosphorus), impurities, colour pigments, traces of metals, and FFA through the use of phosphoric acid (PA) and bleaching earth (BE) at high temperatures $\left(220^{\circ} \mathrm{C}-260^{\circ} \mathrm{C}\right)$. Bleachability test in laboratory is carried out following the Seed Crushers and Oil Processors Association (SCOPA) test method which is regarded as the most suitable test for predicting the refinability of CPO ( $\mathrm{Lin}$ and Gee, 2001).

Prior to bleachability test, the phosphorus content of the solvent extracted mesocarp oil was determined and compared with oil that was mechanically extracted in laboratory. Table 5 shows the phosphorus content of mesocarp oil that were obtained via solvent extraction and mechanical pressing. The phosphorus content in solvent extracted mesocarp oil (91 $\mathrm{mg} \mathrm{kg}^{-1}$ ) was four times higher compared to mesocarp oil that was mechanically pressed $\left(22 \mathrm{mg} \mathrm{kg}^{-1}\right)$. This indicates role of $n$-hexane in extracting phosphorus along with the oil extraction. $\mathrm{CPO}$ obtained from mill has less phosphorus (ca. $11 \mathrm{mg} \mathrm{kg}^{-1}$ ) due to the possibility that water used in milling process might have washed away the phosphorus. Wastewater generated from milling process contains considerably high phosphorus content, about 109-136 $\mathrm{mg} \mathrm{kg}^{-1}$ (Loh et al., 2017).

Bleachability tests were carried out on solvent extracted oil using 1 and $3 \mathrm{wt} \% \mathrm{BE}$ and 0.1-0.5 wt $\%$ PA. Due to high cost of material, palm oil refinery 
TABLE 5. PHOSPHORUS CONTENT IN SOLVENT AND MECHANICAL-PRESSED OIL

\begin{tabular}{lc}
\hline \multicolumn{1}{c}{ Treatment process } & $\begin{array}{c}\text { Phosphorus content } \\
\left(\mathbf{m g ~ k g}^{-1}\right)\end{array}$ \\
\hline $\begin{array}{l}\text { Microwave followed by Soxhlet } \\
(n \text {-hexane) extraction }\end{array}$ & 91 \\
Microwave followed by manual & \\
squeezing & 22 \\
$\begin{array}{l}\text { Steam sterilisation followed by } \\
\text { mechanical press }\end{array}$ & 11 \\
\hline
\end{tabular}

usually use at most, $0.1 \mathrm{wt} \% \mathrm{PA}$ and $2 \mathrm{wt} \% \mathrm{BE}$ for CPO refining (Nu'man and Che Rahmat, 2016). Higher dosages were anticipated for this study due to high phosphorus content in the solvent-extracted oil. Figure 3 shows the phosphorus content in refined solvent extracted oil when 1 and $3 \mathrm{wt} \%$ BE with 0.10.5 wt $\%$ PA were used. Phosphorus content was reduced from 91 to $75 \mathrm{mg} \mathrm{kg}^{-1}$. It was further reduced to $47 \mathrm{mg} \mathrm{kg}^{-1}$ when $0.5 \mathrm{wt} \%$ PA was used. Increasing $\mathrm{BE}$ dosage to $3 \mathrm{wt} \%$ resulted in the reduction of phosphorus content from 33 to $18 \mathrm{mg} \mathrm{kg}^{-1}$ when 0.1 and $0.5 \mathrm{wt} \%$ PA were used, respectively. BE and PA dosage used in this study (3 wt $\%$ and $0.5 \mathrm{wt} \%$, respectively) were higher than for commercial $\mathrm{CPO}$ $\left(11 \mathrm{mg} \mathrm{kg}^{-1}\right)$. This could be one of the drawbacks of using $n$-hexane for palm oil extraction. These results reflected that the measurement of DOBI may not represent the ease of oil refining and thus, may not be applicable to solvent-extracted oil.

\section{Minor Components}

Table 6 shows the composition of vitamin $\mathrm{E}$ in oil that were solvent extracted immediately after microwave heating. $\gamma$-tocotrienol was found to be the major tocol present with concentration ranged from $442-546 \mathrm{mg} \mathrm{kg}$-1 $(34 \%-37 \%)$, followed by $\alpha$-tocopherol (27\%-30\%), $\alpha$-tocotrienol (26\%-29\%), $\delta$-tocotrienol (4\%-9\%) and $\gamma$-tocopherol (2\%-3\%), for all heating durations. Total vitamin E concentrations ranged from $1182-1524 \mathrm{mg} \mathrm{kg}^{-1}$.

In a different scenario where oil extraction was carried out on fruits that were left standing for two days after microwave heating, the vitamin E compositions in the oil are as shown in Table 7. Slight degradations of vitamin E were observed in oil extracted from fruits that were left standing at ambient (c.a. $27^{\circ} \mathrm{C}$ ) for two days upon microwave heating as opposed to immediate extraction as shown in Table $6\left(1347 \mathrm{mg} \mathrm{kg}^{-1}\right)$ and Table 7 (1093 $\mathrm{mg} \mathrm{kg}^{-1}$ ). This is in agreement with the findings by $\mathrm{Ng}$ and Choo (2012) who reported that degradation of vitamin $\mathrm{E}$ occurred in standard $\alpha$-tocopherol solutions that were stored at $-5^{\circ} \mathrm{C}$. Nhan and Hoa (2013) also reported significant vitamin E degradations in pharmaceutical products when exposed to sunlight.

In the oil extracted from fruits that were left standing for two days upon microwave heating, $\gamma$-tocotrienol remained the major tocol, ranging from $305-519 \mathrm{mg} \mathrm{kg}^{-1}(30 \%-39 \%)$, followed by $\alpha$-tocopherol and $\alpha$-tocotrienol $(24 \%-31 \%), \delta$-tocotrienol (4\%$12 \%)$ and $\gamma$-tocopherol (2\%-3\%). The total vitamin E concentration were less (1182-1153 $\left.\mathrm{mg} \mathrm{kg}^{-1}\right)$, which was $2.5 \%$ less for $1 \mathrm{~min}$ heating, $35.9 \%$ (2 min), $5.2 \%$ (3 $\mathrm{min}), 13.5 \%$ (4 min) and $32.9 \%$ (5 min), compared to when there was no delay in oil extraction.

Regardless of the time of oil extraction, $\gamma$-tocotrienol was the major tocol $(30 \%-39 \%)$ in the solvent extracted oil compared to other vitamin $\mathrm{E}$ homologues (Tables 6 and 7). The total vitamin E concentrations in solvent extraction oil were 911$1524 \mathrm{mg} \mathrm{kg}^{-1}$, which was higher compared to commercial CPO (600-800 $\left.\mathrm{mg} \mathrm{kg}^{-1}\right)$. In current milling practice, palm fruits are exposed to high pressure steam for 60-90 min during sterilisation. It is possible that degradation of vitamin E occurred during this process. The relatively shorter heating duration in microwave sterilisation is able to retain the vitamin $\mathrm{E}$ in palm oil. Another possibility is

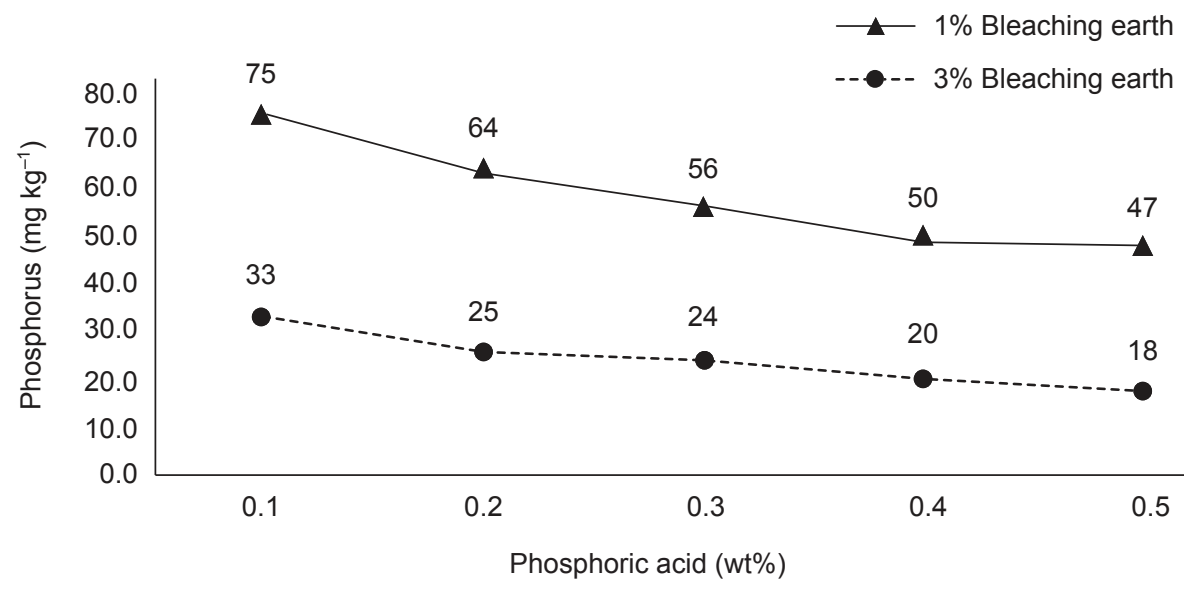

Figure 3. Phosphorus content after refining. Initial phosphorus was $91 \mathrm{mg} \mathrm{kg}^{-1}$. 
TABLE 6. VITAMIN E CONTENT IN OIL EXTRACTED IMMEDIATELY UPON MICROWAVE HEATING OF PALM FRUITS

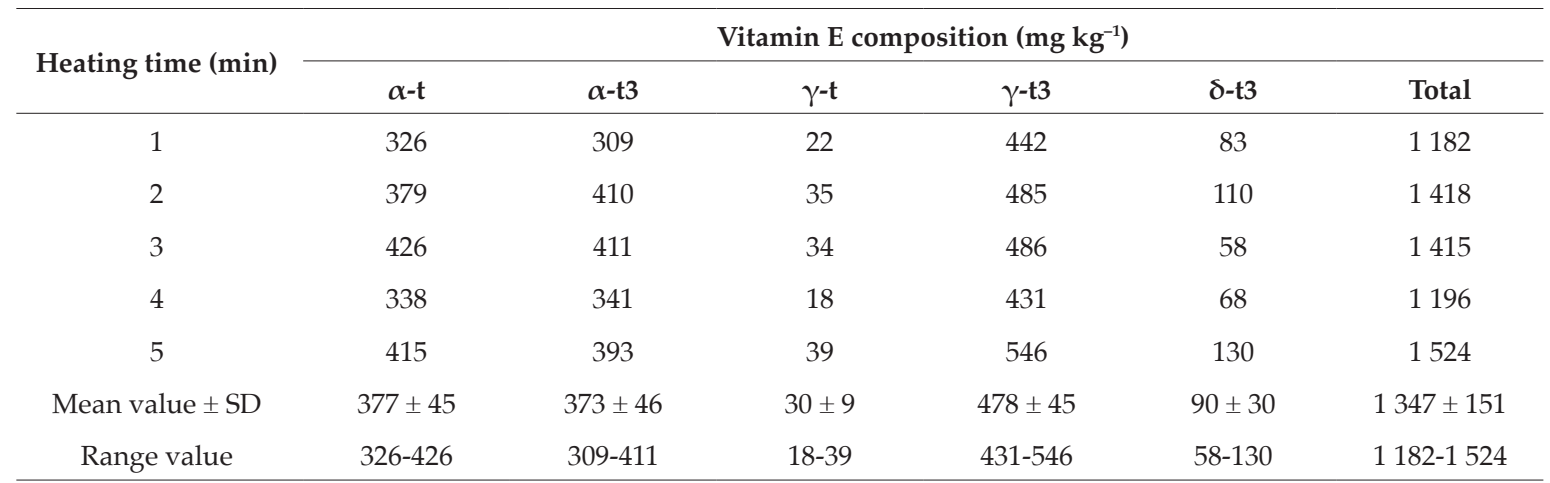

Note: $\mathrm{t}$ - tocopherol; $\mathrm{t} 3$ - tocotrienol; SD - standard deviation.

TABLE 7. VITAMIN E CONTENT IN OIL EXTRACTED AFTER TWO DAYS STANDING UPON MICROWAVE HEATING OF PALM FRUITS

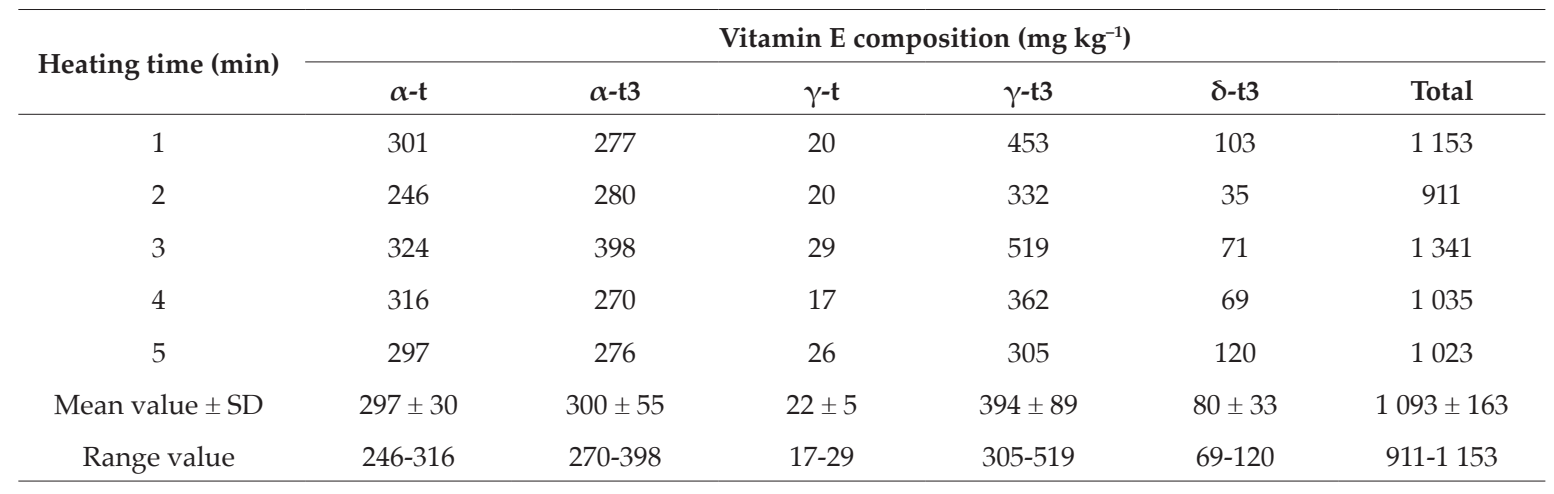

Note: $\mathrm{t}$ - tocopherol; $\mathrm{t} 3$ - tocotrienol; SD - standard deviation.

that microwave sterilisation, coupled with solvent extraction, enabled higher vitamin E extraction efficiency.

Microwave exposure of the palm fruits might cause degradation in minor constituents in palm oil to a certain degree. Malheiro et al. (2011) reported that the degradation pattern of vegetable oils under microwave heating was similar to conventional heating. Tocopherols in soybean oil for example, degraded by $60 \%$ after being heated under microwave for $18 \mathrm{~min}$ (Hassanein et al., 2003). However, sterilisation of palm fruits via microwave does not require long heating duration as a moderate heating duration is adequate to condition the fruits. This would have minimised the degradation effect of the microwave.

Table 8 shows the carotene content in mesocarp oil extracted from fruitlets heated at various durations from freshly heated and two days standing fruitlets. Degradations in carotene by 4\%-14\% were observed when the fruits were left standing for two days after heating. As carotenes are prone to oxidation when exposed to air, leaving it for two days could have led to its degradation. Nevertheless, microwave heating for 1-5 min is still able to retain the carotenes at acceptable level with overall range between 539-652 $\mathrm{mg} \mathrm{kg}^{-1}$. Carotenes, as well as vitamin E, are among micronutrients in vegetable oils that prevent quality deterioration of oil due to their antioxidative property and thus, play an important role during food transformation and storage.

Visual observation on the colour of CPO and oil extracted from microwave heated fruits showed quite similar orangey colour (Figure 4). The orangey

TABLE 8. CAROTENES CONTENT IN MICROWAVE HEATED PALM FRUITS

\begin{tabular}{cccc}
\hline \multirow{2}{*}{$\begin{array}{c}\text { Heating time } \\
\text { (min) }\end{array}$} & $\begin{array}{c}\text { Extraction } \\
\text { immediately } \\
\text { after heating }\end{array}$ & $\begin{array}{c}\text { Extraction } \\
\text { two days } \\
\text { after heating }\end{array}$ & $\begin{array}{c}\text { Degradation } \\
(\%)\end{array}$ \\
\hline 1 & 635 & 548 & 14 \\
2 & 626 & 539 & 14 \\
3 & 610 & 587 & 4 \\
4 & 652 & 612 & 6 \\
5 & 619 & 556 & 10 \\
Mean value & $628 \pm 16$ & $568 \pm 30$ & 10 \\
\pm SD & & & $4-14$ \\
\hline Range value & $610-652$ & $539-612$ & \\
\hline
\end{tabular}

Note: SD - standard deviation. 


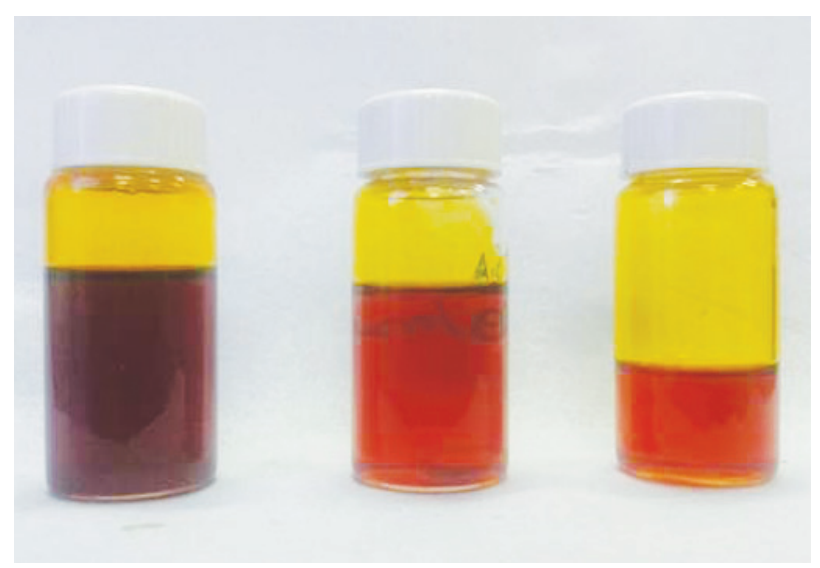

Figure 4. Colour difference of (a) palm fibre oil, (b) crude palm oil, and (c) mesocarp oil extracted from microwave heated palm fruits.

colour of oil indicates the presence of carotenes. Deeper oil colour resembles higher carotene concentrations (Rusnani et al., 2012). In this study, carotenes content in oil extracted from microwave heated palm fruits $\left(539-652 \mathrm{mg} \mathrm{kg}^{-1}\right)$ is comparable to the carotenes content in CPO (500-700 $\mathrm{mg} \mathrm{kg}^{-1}$ ). This explains the similarity in the colour as shown in Figure 4. In a study by Rusnani et al. (2012), higher carotene concentrations (1716-2083 $\mathrm{mg} \mathrm{kg}^{-1}$ ) was found in palm pressed fibre oil (PFO) which corresponded to deep red colour. In normal practice, carotenes are degraded and removed in $\mathrm{CPO}$ physical refining process, where the colour of oil changed from orangey to pale yellow (SzydłowskaCzerniak et al., 2011), although the original intention of refining was to remove pigments and impurities. Removal of pigments and impurities occurred at extreme conditions $\left(240^{\circ} \mathrm{C}-260^{\circ} \mathrm{C}\right)$ with the aid of chemicals and bleaching agents. Therefore, it is concluded that heating at shorter duration or at common sterilisation temperature of $130^{\circ} \mathrm{C}$ does not fully degrade the carotenes.

\section{Harvesting of Detached Fruitlets}

The yield and quality of mesocarp oil extracted from microwave heated detached fruits that were collected over 21 days since the first fruit ripened and detached from the bunch were investigated. The FFA content in oil from fruits collected in the first week was below 3\%, and gradually increased to above 5\% after day 12 (Figure $5 a$ ). It was also observed that after a few days, some of the fruits deteriorated on its bunch, as they were detached, but did not fall to the ground due to resistance from spikes and the position of the fruits at inner bunch.

The oil yield varied from $23.8 \%-50.4 \%$ (Figure $5 b$ ). However, the results may not represent the actual oil content of the FFB as the fruits from outer layer generally have thicker mesocarp, thus, contain more oil, than those from the inner FFB layer. On average, there was an increasing trend in oil yield from $31.7 \%$ when the first fruit dropped to $50.4 \%$ on the $21^{\text {st }}$ day. The oil yield, together with FFA profile, showed that while overripe fruits yield more oil, development of FFA was also rapid (7.0\%, maximum) (Figure $5 a$ ).

DOBI values in oil extracted from microwaved detached fruits decreased gradually from 4-5 to 1-2 after 20 days (Figure 5c). The DOBI was badly affected after day 19 which saw it fell to below 2.3, which is the minimum level set by PORAM. However, the DOBI in this study is not as badly affected compared to deterioration of FFA as low DOBI is usually caused by prolonged fruits sterilisation, over heating of oil during storage and high percentage of unripe fruits (Jusoh et al., 2013).

Palm mesocarp oil consists of mainly triglycerides, which can be hydrolysed by lipase enzyme to form undesired FFA. The formation of FFA starts when the fruit ripened and higher FFA content can be found in overripe fruits compared to ripe and underripe fruits (Junaidah et al., 2015). The same trend is observed in this study where oil from detached fruits collected in subsequent days after the first fruit ripened and detached from the bunch had higher FFA content compared to the oil from fruits collected on the first day.

While FFA content reflects the quality of oil, DOBI, on the other hand, shows deterioration of the oil by oxidation, and determines the difficulty level of subsequent refining process (Lin and Gee, 2001). Oxidative stability determines the stability of the oil when exposed to certain condition, e.g. high temperature and air. Oxidation level can be determined using various measurements such as peroxide value and para-anisidine value. Stability is important for vegetable oils as they are commonly used for cooking and deep frying. Figure $5 d$ shows the induction time of the oil extracted from detached fruitlets for oxidative stability test. Palm oil (olein) usually has longer induction time when subjected to Rancimat oxidative stability test for about $28 \mathrm{hr}$ compared to other vegetable oils (Azmil Haizam et al., 2016). CPO's induction time is about $15-20 \mathrm{hr}$ at $120^{\circ} \mathrm{C}$. It was found that the induction time for the oil obtained from microwaved detached fruitlets decreased from $15.18 \mathrm{hr}$ for the detached fruits on the first day to $5.28 \mathrm{hr}$ for fruits detached on the $21^{\text {st }}$ day. This finding is in parallel with the deterioration trend of antioxidants in the oil, namely vitamin $\mathrm{E}$ and carotenes.

Vitamin E and carotenes content in the oil extracted from daily collection of detached fruitlets are shown in Figures $5 e$ and $5 f$. There is a continuous and significant decrement of vitamin $\mathrm{E}$ and carotenes content over the days. Vitamin $\mathrm{E}$ and carotenes content decreased from 771 to $206 \mathrm{mg} \mathrm{kg}^{-1}$ and 678 to $185 \mathrm{mg} \mathrm{kg}^{-1}$, respectively. This could also reflect the deterioration in the mesocarp oil as vitamin $\mathrm{E}$ is a fat-soluble compound with distinctive antioxidative 


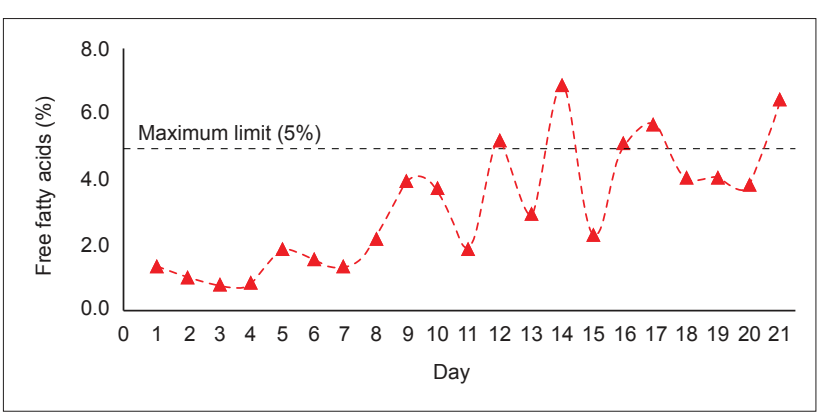

(a)

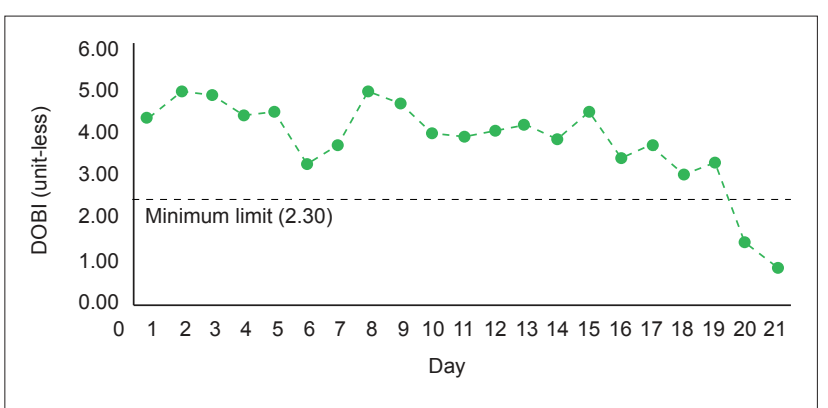

(c)

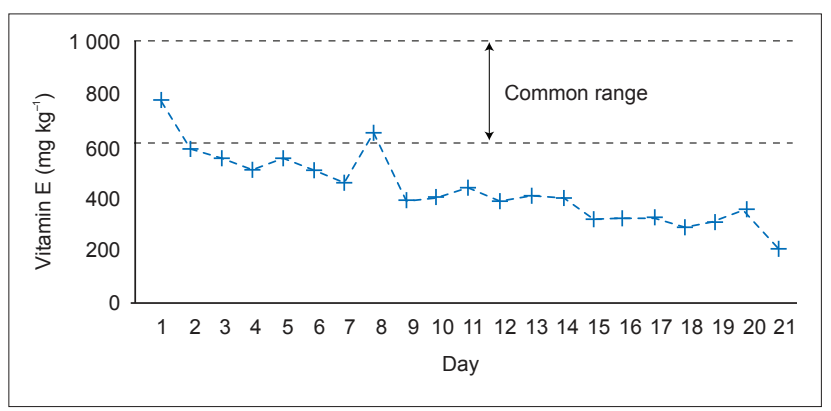

(e)

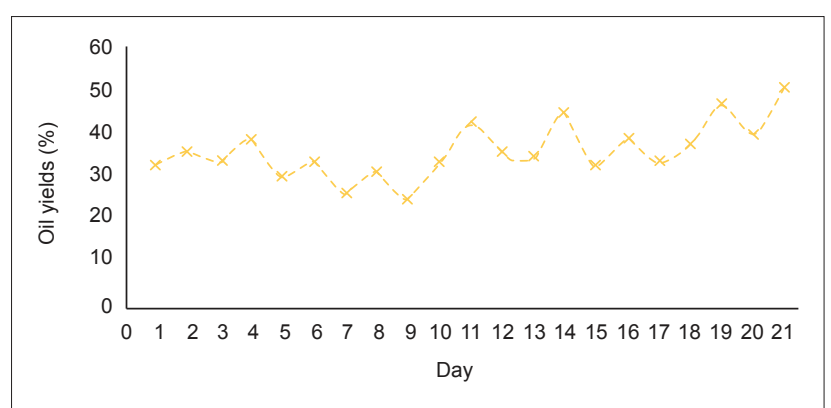

(b)

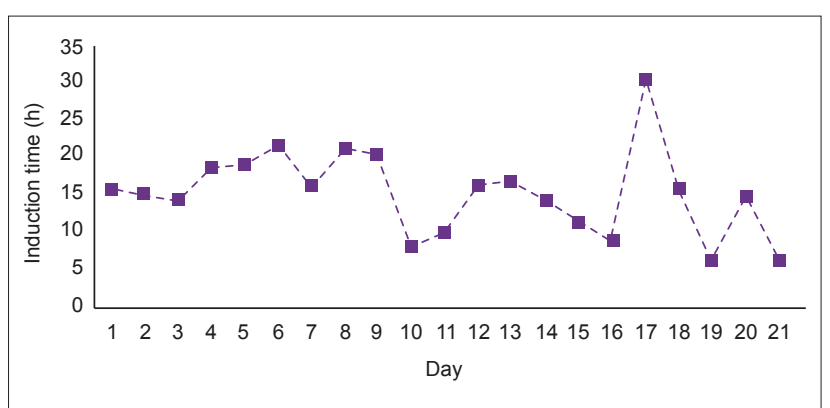

(d)

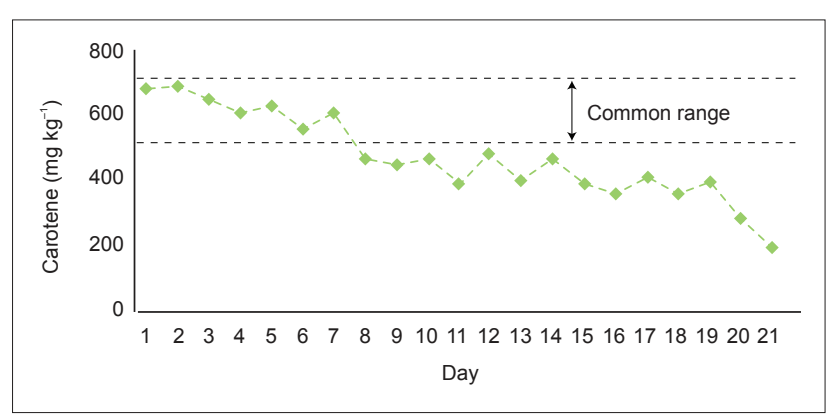

(f)

Figure 5. (a) Free fatty acid, (b) oil yield, (c) deterioration of bleachability index (DOBI), (d) Rancimat oxidative stability, (e) vitamin $E$, and (f) carotene content of the mesocarp oil over days.

property that protects the oil. Decreased level of vitamin E means that the oil is less protected against oxidation. Oxidation stability of the oil conducted using Rancimat method in this study showed significant decrement of induction time from 15.18 to $5.28 \mathrm{hr}$ (Figure 5d). This makes sense as the deterioration of antioxidant in the oil, namely vitamin E, reduces the oxidation stability of the oil.

Taking into consideration the quality of oil extracted from the detached fruitlets over 21 days, harvesting of only fruitlets while leaving the EFB at plantations is not a practical approach at the moment, but holds great benefits if it can be realised. Processing only the detached fruits that fell on the ground while leaving the bunch at the tree may result in higher oil recovery, but with risk of oil quality deterioration. Moreover, collecting detached fruitlets at the plantations requires additional mobile machineries and may not be feasible due to vast planting areas and variable land topographies, as well as bulky structure of the FFB.
A mechanism to separate fruitlets from the bunch may have to be developed in the future to make microwave sterilisation for palm oil processing more effective and feasible. The other way is to separate processing of oil palm fruitlets and bunches; the former sterilised using microwave and the latter using steam. Since FFB consignment consists of 8\%-10\% loose fruits, only a small size of microwave equipment would be required to cater for loose fruits processing. This practice could potentially reduce mill's oil loss due to absorption of oil from mesocarp to stalk and bunch in conventional steam sterilisation.

\section{CONCLUSION}

Microwave heating of palm fruitlets had comparable effect as steam sterilisation, except that current steam sterilisation cooks the whole bunch instead of only fruitlets in microwave heating. The mesocarp 
oil extracted using $n$-hexane had comparable, if not, better quality than $\mathrm{CPO}$ with average FFA, DOBI, oxidative stability, carotenes and vitamin E content of $1.14 \%, 4.2 \%$ and $18.31 \mathrm{hr}, 624 \mathrm{mg} \mathrm{kg}^{-1}$ and 1347 $\mathrm{mg} \mathrm{kg}^{-1}$, respectively. Extraction of oil using solvent resulted in phosphorus being extracted as well with higher phosphorus content about $91 \mathrm{mg} \mathrm{kg}^{-1}$ recorded compared to $22 \mathrm{mg} \mathrm{kg}^{-1}$ phosphorus in oil extracted by press. High BE ( $3 \mathrm{wt} \%)$ and PA $(0.5$ $\mathrm{wt} \%$ ) dosages are needed to reduce the phosphorus content from 91 to $17.9 \mathrm{mg} \mathrm{kg}^{-1}$ which also reflects difficulty in oil refining. While its DOBI value - a rapid assessment for the ease of refining - was good, bleachability test showed otherwise. As DOBI value was widely used for mechanically pressed CPO, similar method may not be applicable to solventextracted oil. This is one of the key results that could be of future reference for other researchers.

Daily collection of detached fruits from the plantation may increase the capacity and thus, feasibility of microwave sterilisation. Oil production can be maximised as well due to only ripe, detached fruits are processed. However, quality of the oil obtained from such fruitlets deteriorated significantly over days due to the delayed harvesting approach. FFA, DOBI, oxidative stability, vitamin E and carotene content deteriorated from 1.3\%, 4.32, $15.18 \mathrm{hr}, 771 \mathrm{mg} \mathrm{kg}^{-1}$ and $678 \mathrm{mg} \mathrm{kg}^{-1}$ to $6.5 \%, 0.86$, $5.28 \mathrm{hr}, 206 \mathrm{mg} \mathrm{kg}^{-1}$ and $185 \mathrm{mg} \mathrm{kg}^{-1}$ respectively.

\section{ACKNOWLEDGEMENT}

The authors thank the Director-General of MPOB for financial support and for the approval to publish this article. We also thanked the staff of Milling Unit, MPOB for their assistance throughout the study.

\section{REFERENCES}

Ahmad Borhan, A N; Mohd Arif, S; Mohd Nasir, A; Chan, K W and Burhanuddin, A S (2004). Economic feasibility of organic palm oil production in Malaysia. Oil Palm Industry Economic J., 4: 29-38.

Ahmed, Y; Yaakob, Z; Akhtar, P and Sopian, K (2015). Production of biogas and performance evaluation of existing treatment processes in palm oil mill effluent (POME). Renew. Sust. Energ. Rev., 42: 1260-1278.

Ainie, K; Siew, W L; Tan, Y A; Nor Aini, I; Mohtar, Y; Tang, T S and Nuzul Amri, I (2005). MPOB Test Methods. MPOB, Bangi.

Azmil Haizam, A T; Karimah, A; Miskandar, MS and Choo, Y M (2016). Rancimat test for measuring the oxidative stability of cooking oils upon prolonged frying. J. Oil Palm Res., 28: 531-535.
Cheng, S F and Chuah, C H (2011). Microwave pretreatment: A clean and dry method for palm oil production. Ind. Crops Prod., 34: 967-971.

Chow, M C and Ma, A N (2007). Processing of fresh palm fruits using microwaves. J. Microw. Power Electromagn. Energy, 40: 165-173.

Corley, R H V and Tinker, P B H (2015). Care and maintenance of oil palms. The Oil Palm. Wiley Blackwell, United Kingdom. p. 290-328.

George, E A (2011). Solvent extraction: Edible oil processing. AOCS Lipid Library. https: / / lipidlibrary.aocs.org/ edible-oil-processing, accessed on 1 January 2020.

Hassanein, M M; El-Shami, S M and Hassan ElMallah, M (2003). Changes occurring in vegetable oils composition due to microwave heating. Grasas Aceites, 54: 343-349.

Junaidah, M J; Norizzah, A R; Zaliha, O and Mohamad, S (2015). Optimisation of sterilisation process for oil palm fresh fruit bunch at different ripeness. Int. Food Res. J., 22: 275-282.

Jusoh, J M; Rashid, N A and Omar, Z (2013). Effect of sterilisation process on deterioration of bleachability index of crude palm oil extracted from different degree of oil palm ripeness. Int. J. Biosci. Biochem. Bioinforma., 3: 322-327.

Kandiah, S; Basiron, Y; Suki, A; Taha, R M; Hwa, T Y and Sulong, M (2006). Continuous sterilization: The new paradigm for modernising palm oil milling. J. Oil Palm Res., Special Issue: 144-152.

Komarov, V; Wang, S and Tang, J (2005). Permittivity and measurements. Encyclopedia of RF and microwave engineering. John Wiley and Sons, New York. p. 3693-3709.

Kushairi, A and Abd Rahim, S (2017). Innovations in oil palm mechanisation. Planter, 93: 119-130.

Kushairi, A; Loh, S K; Azman, I; Elina, H; Meilina, O A; Zainal Bidin, M N I; Razmah, G; Shamala, S and Parveez, G K A (2018). Oil palm economic performance in Malaysia and R\&D progress in 2017. J. Oil Palm Res., 30: 163-195.

Lin, S W and Gee, P T (2001). Deterioration of bleachability index. Inform. AOCS, 12: 1183-1187.

Loh, S K; Nasrin, A B; Mohamad Azri, S; Nurul Adela, B; Muzzammil, N; Daryl Jay, T; Stasha Eleanor, R A; Lim, W S; Choo, Y M and Kaltschmitt, M (2017). First report on Malaysia's experiences 
and development in biogas capture and utilization from palm oil mill effluent under the economic transformation programme: Current and future perspectives. Renew. Sust. Energ. Rev., 74: 1257-1274.

Malheiro, R; Casal, S; Ramalhosa, E and Pereira, J A, (2011). Microwave heating: A time saving technology or a way to induce vegetable oils oxidation? Advances in induction and microwave heating of mineral and organic materials. IntechOpen, London. p. 597-614.

$\mathrm{Ng}, \mathrm{M} \mathrm{H}$ and Choo, Y M (2012). Chromatographic analyses of tocopherols and tocotrienols in palm oil. J. Chromatogr. Sci., 50: 283-286.

Nhan, P P and Hoa, N K (2013). Effect of light and storage time on vitamin $\mathrm{E}$ in pharmaceutical products. Br. J. Pharmacol., 4: 176-180.

Nu'man, A H and Che Rahmat, C M (2016). Prediction model based on artificial neural network for industrial bleaching and degumming process for crude palm oil. Int. J. Eng. Innov. Technol., 6: 3238.

Parveez, G K A; Hishamuddin, E; Loh, S K; OngAbdullah, M; Salleh, KM; Bidin, MNIZ;Sundram, S; Hasan, Z A A and Idris, Z (2020). Oil palm economic performance in Malaysia and R\&D progress in 2019. J. Oil Palm Res., 32: 159-190.

Ramli, A (2011). World palm oil supply, demand, price and prospects - Focus on Malaysian and Indonesian palm oil industries. Oil Palm Industry Economic J., 11: 13-25.
Rusnani, A M; Abdul Wahab, M and Choo, Y M (2012). Properties of residual palm pressed fibre. J. Oil Palm Res., 24: 1310-1317.

Sarah, M (2018). Carotenoids preservation during sterilization of palm fruit using microwave irradiation. ARPN J. Eng. Appl. Sci., 13: 1009-1014.

Sosa-Morales, M E; Valerio-Junco, L; López-Malo, A and García, H S (2010). Dielectric properties of foods: Reported data in the $21^{\text {st }}$ century and their potential applications. LWT, 43: 1169-1179.

Statista (2019). Vegetable oils: Global consumption by oil type. https://www.statista. com / statistics / 263937 / vegetable-oils-globalconsumption/, accessed on 1 November 2019.

Sukaribin, N and Khalid, K (2009). Effectiveness of sterilisation of oil palm bunch using microwave technology. Ind. Crops Prod., 30: 179-183.

Swoboda, P A T (1982). Bleachability and the DOBI (determination of bleachability index in palm oil). Oil Palm Bulletin, 5: 28-38.

Szydłowska-Czerniak, A; Trokowski, K; Karlovits, $\mathrm{G}$ and Szłyk, E (2011). Effect of refining processes on antioxidant capacity, total contents of phenolics and carotenoids in palm oils. Food Chem., 129: 1187-1192.

Umudee, I; Chongcheawchamnan, M; Kiatweerasakul, M and Tongurai, C (2013). Sterilization of oil palm fresh fruit using microwave technique. Int. J. Chem. Eng. Appl., 4: 111-113. 